\section{Human immunodeficiency virus and its effects on the visual system}

\author{
Michael W. Stewart \\ Department of Ophthalmology, Mayo \\ College of Medicine, Jacksonville, FL, \\ USA
}

\section{Abstract}

During the first 15 years of the AIDS epidemic patients experienced a high incidence of blindness due to cytomegalovirus (CMV) retinitis and other severe ocular opportunistic infections. Highly active anti-retroviral therapy, introduced in 1996, dramatically decreased the incidence of CMV retinitis. Though CMV retinitis still causes $40 \%$ of vision loss in AIDS patients, other conditions such as immune reconstitution uveitis, cataracts, and a significant othercategory -which most investigators believe is directly due to HIV - comprise the majority of cases. HIV causes vascular abnormalities of the conjunctiva and retina in the majority of AIDS patients, as well as retinitis, anterior and posterior uveitis and vasculitis. HIV frequently causes an optic neuropathy and is responsible for the majority of eye movement disorders among HIV patients. Physicians need to be aware that these problems may be the initial manifestation of HIV infections or a sign of highly active anti-retroviral therapy (HAART) failure. Therefore, patients with identifiable risk factors for AIDS who present with ophthalmologic conditions of unknown etiology should be considered for HIV testing. Finally, anti-retroviral therapy has been reported to cause asymptomatic deposits as well as degenerative conditions of both the anterior and posterior segments of the eye.

\section{Introduction}

The groundbreaking reports of 5 young men afflicted with unusual opportunistic infections due to an acquired immunodeficiency disorder ushered in the AIDS era in 1981.,1,2 Affected patients rapidly succumbed to the lethal complications of opportunistic infections (pneumocystis carinii pneumonia, cytomegalovirus (CMV) disease, cryptococcal meningitis, candidiasis) and tumors (Kaposi's sarcoma, lymphoma).

Although most investigators correctly attributed the immunodeficiency to an unidentified microbe, it took 2 years before identification of the HTLV-III (human T-lymphocyte virus), later named HIV-1 (human immunodeficiency virus). Although targeted anti-retroviral therapy began with the introduction of zidovudine, a nucleoside reverse transcription inhibitor, in 1987, life expectancy was extended by at most 1 year. Unfortunately, many patients developed drug-induced neutropenia that frequently required cessation of therapy or prevented the co-administration of drugs with similar toxicity profiles that were given to control opportunistic infections (e.g. ganciclovir for CMV retinitis). As a result, long-term survival was rare.

The introduction of highly active anti-retroviral therapy (HAART) in 1996, originally defined as two nucleoside reverse transcriptase inhibitors (NRTIs) combined with a protease inhibitor (PI), and recently (2004) expanded by the DHHS/Kaiser panel to include a PI, a non-nucleoside reverse transcriptase inhibitor, one of the NRTIs (abacavir or tenofovir), an integrase inhibitor (e.g., raltegravir), or an entry inhibitor (e.g., maraviroc or enfuvirtide), ${ }^{3}$ became a watershed event in the therapy of HIV-infected patients. Successfully treated patients experienced several measurable improvements. The rate of viral replication significantly decreased and, for the first time since 1981, patients experienced reconstitution of their immune systems. As a direct consequence, the incidence rates of many opportunistic infections fell, with CMV retinitis dropping by $80 \%{ }^{4}$ At the same time, immune reconstitution inflammatory syndromes (IRIS) emerged, with immune reconstitution uveitis (IRU) affecting $15 \%$ to $25 \%$ of AIDS patients. ${ }^{5}$

During the pre-HAART era, retinal necrosis or detachment due to CMV caused more than 90\% of AIDS-related vision loss. Following the introduction of HAART, the incidence of vision loss decreased by more than $50 \%$, even after excluding patients with infectious retinopathies. CMV retinitis now accounts for only $40 \%$ of vision loss $(<20 / 200)$, cataracts are responsible for $25 \%$, and in $10 \%$ the reason for vision loss cannot be determined. ${ }^{6}$ Although $10 \%$ of AIDS-related vision loss has been termed idiopathic, many investigators believe that this results from HIV damage to the retina and optic nerve.

Unfortunately, HAART fails in up to $50 \%$ of AIDS patients due to non-compliance, side effects of the drugs, adverse drug interactions, or HIV resistance. ${ }^{7}$ As a result, up to $69 \%$ of newly diagnosed cases of CMV retinitis are due to HAART failure, as defined by either persistently low $\mathrm{CD}^{+}$T-lymphocyte counts or high HIV RNA blood levels. ${ }^{8}$ In addition to being at risk for developing opportunistic infections, these patients experience more HIV-related complications.

Several in-depth reviews have covered the characteristics of CMV retinitis and other ocular opportunistic infections. ${ }^{9,10}$ This manuscript, however, will discuss the characteristics and direct consequences of HIV infection and anti-retroviral treatment on the visual system.
Correspondence: Michael W. Stewart, Department of Ophthalmology, Mayo College of Medicine, 4500 San Pablo Road, Jacksonville, FL 32224, USA.

Tel. +1.904.953.2232 - Fax: +1.904.953.7040.

E-mail: stewart.michael@mayo.edu

Key words: HIV, AIDS, vision, eye, retina.

Conflict of interest: the author has the following interests. Regeneron Pharmaceuticals: research support, Consultancy fees; Bayer Pharmaceuticals: research support.

Received for publication: 25 October 2011. Revision received: 5 February 2012.

Accepted for publication: 6 February 2012.

This work is licensed under a Creative Commons Attribution NonCommercial 3.0 License (CC BYNC 3.0).

(C) Copyright M.W. Stewart, 2012

Licensee PAGEPress, Italy

Infectious Disease Reports 2012; 4:e25

doi:10.4081/idr.2012.e25

\section{HIV infection}

HIV infection causes both activation and destruction of the host's immune system. The initial HIV infection is confronted by the expected inflammatory response by the host against the virus. This is characterized by polyclonal activation of both T-lymphocytes and Blymphocytes with the release of inflammatory cytokines. Patients exhibit a 3 to 4 fold increase in the production of both $\mathrm{CD} 4^{+}$and CD8+ T-lymphocytes. T-lymphocyte turnover is promoted by the production of interleukin- 6 , interleukin-1, interleukin-2 and tumor necrosis factor (TNF)- $\alpha$, all of which promote HIV replication. This cascade further accelerates the destruction of the immune system. Advancing infection is accompanied by further CD4+ T-lymphocyte destruction and worsening of the immune status.

Under the influence of the thymus, lymphocytes mature from stem cells and carry on their surfaces unique receptors for various antigens. On the surface of each T-lymphocyte resides 1 receptor, which is specific to a unique antigen. Healthy individuals have a register of T-lymphocytes that allow them to respond to various foreign stimuli. Thus, $\mathrm{CD} 4^{+}$ cells, which are responsible for long-term memory, are responsible for organizing the immune system's response against specific invading organisms.

A CD4+ T-lymphocyte that has never encountered a foreign antigen is said to be at ground state (G0) and is called a naive cell. Once exposed to an antigen, the $\mathrm{CD} 4^{+}$cell activates 
and replicates; these clones are now considered memory cells.

As the HIV infection progresses the patient experiences a blunted response to new antigens followed by a decreased response to recall antigens. This is due to a loss of CD4+ memory cells accompanied by an inability to activate and subsequently replicate new $\mathrm{CD}^{+}$cells. The progressive loss of $\mathrm{CD} 4^{+}$clones puts the patient at increasing risk of opportunistic infections. Therefore, the $\mathrm{CD}^{+}{ }^{+}$count is an instantaneous overall measure of the patient's susceptibility to opportunistic infections. Additionally, the HIV load is a predictor of the future likelihood of further erosion in the patient's immune status. ${ }^{11}$

Most of the $\mathrm{CD} 4^{+}$cells lost due to HIV infection are the naive ones, ${ }^{12}$ thereby decreasing the body's ability to respond to new antigens. With reconstitution of the immune system due to successful HAART, memory $\mathrm{CD} 4^{+}$cells are the first to increase, followed later by an increase in naive $\mathrm{CD} 4^{+}$cells. ${ }^{13}$ Despite apparent reconstitution of the immune system, however, gaps in the immune system's register frequently remain. Since thymus involution occurs during the teenage years, infected patients are frequently unable to mount an immune response to new antigens. ${ }^{14}$

HIV has been found in mononucleated white blood cells ${ }^{15}$ and HIV infected macrophages which may act by releasing neurotrophic factors, enzymes, or cytokines, or by directly releasing virions, enveloping glycoproteins, or inflammatory mediators. Elevated levels of cytokines, particularly TNF- $\alpha$, interleukin-1 and interleukin-2, have been reported in the serum of AIDS patients. These cells probably play an important role in promoting HIV infection of eye and central nervous system.

A major deficiency of HAART concerns its inability to prevent HIV-infected cells of the monocyte-macrophage line from establishing latent infections within the immunoprivileged central nervous system. Monocytes circulate within the blood stream for 3 days before migrating into tissues where they differentiate into macrophages. When they cross the bloodbrain barrier they differentiate into perivascular, meningeal or choroidal plexus macrophages, or microglia, after which they remain latent within the central nervous system for extended periods of time. ${ }^{16}$ Passage of infected macrophages into the brain, referred to as the Trojan Horse hypothesis, is one of the mechanisms by which HIV infects the CNS. ${ }^{17}$ These cells contain a potentially large reservoir of HIV that escapes surveillance by the immune system. ${ }^{18}$ When exposed to the correct stimulus, frequently an opportunistic infection, the macrophages reactivate and shed virions. Additionally, reactivated CNS macrophages can return to the peripheral circulation, thereby causing recurrent viremia. ${ }^{19,20}$
Unlike infected $\mathrm{CD}^{+}$lymphocytes, CNS macrophages survive for weeks to months, retain their viability, and continue to shed low levels of virions. Activation of these macrophages is believed responsible for AIDS related dementia. ${ }^{21}$ Furthermore, CNS infiltration by HIV-infected monocytes leads to phosphorylation of junctional proteins and activation of matrix metalloproteinases, thereby causing breakdown of the blood-brain barrier which further exposes the host to opportunistic infections of the CNS. ${ }^{22}$

Table 1. HIV related lesions of the visual system are listed by location.

\section{Ocular}

a. Anterior segment

i. Cornea

1. Ulceration

2. Deposits

3. Keratoconjunctivitis sicca

ii. Anterior chamber

1. Uveitis

iii. Iris

1. Deposits

iv. Lens

1. Cataracts

b. Posterior segment

i. Vitreous

1. Uveitis

2. Other

ii. Retina

1. Vasculopathy

a. HIV retinopathy

b. Retinal vein occlusions

c. Retinal artery occlusions

2. Retinitis

3. Subclinical loss of nerve fiber layer

4. Macular changes
a. Edema
b. Epiretinal membrane
c. Ischemia

5. Drug toxicity

6. Choroidal effusions

7. Neuroretinal disorder

Periocular

a. Conjunctiva

i. Vasculopathy

ii. Granulomas

b. Eyelids

i. Blepharitis

ii. Tricomegaly

c. Other

\section{Neurologic}

a. Optic nerve
i. Optic neuritis
ii. Neuroretinitis
iii. Ischemic optic neuropathy
iv. Subclinical neuropathy

b. Brain

i. Leukoencephalopathy

ii. Optic tract demyelination

iii. Ocular movement disorders
HIV can be found in most mucous membrane secretions, including semen, cervical secretions and saliva..$^{15}$ Additionally, HIV has been found in all ocular fluids: tears, aqueous and vitreous. ${ }^{23}$

\section{Ocular findings}

A listing of ophthalmologic findings due to HIV can be found in Table 1 . 


\section{Retinopathy}

HIV infection leads to microvascular changes in several vascular beds: conjunctiva, optic disc and, most commonly, the retina. HIV retinopathy is seen in $40 \%$ to $100 \%$ of infected patients and has been found in $89 \%$ of autopsy specimens. ${ }^{24,25}$ The likelihood of a patient developing clinically apparent retinopathy depends somewhat upon the patient's lowest $\mathrm{CD} 4^{+}$count, as retinopathy occurs in $45 \%$ of patients with counts below 50 cells/uL but in only $6 \%$ of patients with counts greater than 50 cells/ $\mu \mathrm{L}$. HIV infected children have a lower incidence of ocular involvement (20\%) than do adults. ${ }^{26}$ Also, retinopathy is seen less commonly in subSaharan Africa, perhaps due to genetic differences, environmental conditions pertaining to organisms, early mortality, poor access to healthcare or fewer screening programs.

HIV vasculopathy is characterized by microaneurysms, telangiectasia, retinal hemorrhages, and cotton wool spots (CWSs) (Figure 1). The CWSs may be transient, remaining visible for only a few weeks. ${ }^{27}$ Although most patients with retinal vasculopathy have no visual complaints, large cotton wool spots may cause either focal scotomas by preventing light penetration to the photoreceptors, or arcuate scotomas due to retinal nerve fiber layer damage.

Vision loss due to microvasculopathy is usually mild and insidious but ischemic maculopathy, characterized by multiple cotton wool spots and blot hemorrhages near the fovea, may cause sudden loss of vision in $3 \%$ of patients. ${ }^{24}$ The presenting visual acuity in these patients may range from $20 / 20$ to counting fingers, with final visual acuities worse than 20/200 in 5 of 7 cases. ${ }^{7}$ Two cases of extensive bilateral retinal ischemia due to HIV have been described. ${ }^{28}$ Ischemic maculopathy has also been described in a patient with zidovudine induced anemia. ${ }^{29}$ Numerous large cotton wool spots may sufficiently damage the nerve fiber layer to result in optic disc atrophy.

HIV can cause a non-progressive, non-hem-

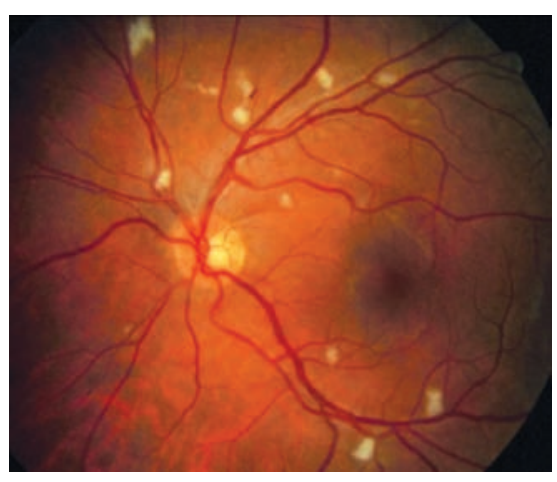

Figure 1. Several cotton wool spots, typical of HIV retinopathy, are seen in this photo. orrhagic white-gray or yellow, multifocal peripheral retinitis with vitritis and retinal vasculitis that resembles syphilitic retinitis. ${ }^{30}$ Unlike HIV retinopathy and CMV retinitis, these findings occur in patients with $\mathrm{CD}^{+}$ counts greater than 120 . As expected, this retinitis responds well to HAART.

Serous detachment of the macula and macular edema can be seen with IRU. Though laser photocoagulation treatment of macular edema has been attempted, treatment is probably ineffective. ${ }^{24}$ Ciliochoroidal effusions have been seen, though the reason for their formation is unclear. ${ }^{31}$

Although retinal arterial and venous occlusions in AIDS patients are most often associated with CMV retinitis and lymphoproliferative disorders, they have been identified as isolated findings. Central retinal vein occlusions are believed to occur in $0.64 \%$ of AIDS patients, a rate similar to an older segment of the general population ( $>50$ years). Three cases of branch retinal vein occlusions were reported by Park et al. ${ }^{32}$ Although the exact reason for the occlusions is unknown, they presumably occur due to blood hyperviscosity. ${ }^{24,32}$ Proposed etiologies for this include circulating immune complexes, clotting abnormalities, lupus anticoagulant and TNF- $\alpha .^{33}$

A neuroretinal disorder, characterized by a vague recognition of loss of vision combined with loss of contrast sensitivity, occurs in $12 \%$ of patients. ${ }^{34}$ Mitochondrial dysfunction has been discovered in these patients. ${ }^{35-37}$

Optical coherence tomography (OCT) has consistently detected thinning of the retinal nerve fiber in patients with observed retinal abnormalities. The greatest loss of nerve fiber layer occurs in areas that contained previous CWSs. ${ }^{38}$ An OCT study that measured retinal thickness at specific points that had CWSs photodocumented 10 years previously showed $43 \%$ thinning of the ganglion cell layer and $25 \%$ thinning of the inner nuclear layer. ${ }^{39} \mathrm{HIV}$ patients without opportunistic retinitis demonstrate greater optic cup depth, cross sectional analysis, and discriminant analysis compared to normals. Nerve fiber layer loss is greater in patients with $\mathrm{CD} 4^{+}$counts below 100 , compared to both patients with counts over 100 and normal controls (90 vs. 103 vs. 103). ${ }^{39,40}$ Not surprisingly, greater nerve fiber layer loss occurs in patients with $\mathrm{CMV}$ retinitis than in those with only HIV retinopathy.

Nerve fiber layer photography discovered slit-like defects, wide sectoral defects and generalized atrophy of the retina. Although some defects correlated with CWSs, most were from areas without observable retinal pathology. Up to $40 \%$ of ganglion cells appeared to be lost. ${ }^{41}$ Scanning laser ophthalmoscopy has also shown NFL loss.

Several psychophysical abnormalities have been discovered in HIV patients. Pattern- evoked electroretinograms are diminished in early HIV infections, whereas visual evoked responses, which are normal early in the disease process, become diminished later. This suggests that HIV damages the retina before either the optic nerves or central nervous system. Pattern recognition and color vision are frequently diminished. ${ }^{27}$ Multifocal electroretinograms frequently reveal retinal conduction abnormalities in HIV patients. Prolonged latencies suggest that HIV-related damage preferentially involves the inner retina rather than the photoreceptor layer. ${ }^{42}$ Since these problems have been found in patients with low and high $\mathrm{CD} 4^{+}$counts, HAART probably does not protect the retina from HIV-related conduction damage..$^{43}$

Impaired contrast sensitivity occurs in up to $12.5 \%$ of patients and correlates with low CD4+ counts. When compared to normals, $39 \%$ of HIV patients have diminished mean deviation and $33 \%$ have diminished pattern specific deviation on visual field testing. Ten percent of patients, particularly those with impaired contrast sensitivity, have significant decreases in reading speed. ${ }^{44}$ Not surprisingly, abnormalities in one measure of visual function strongly correlate with abnormalities of other functions.

The histopathologic findings of HIV retinopathy, pericyte necrosis, basement membrane thickening and endothelial cell swelling, resemble those seen in diabetic retinopathy. ${ }^{45}$ Although the etiology of HIV retinopathy is not completely understood, the following processes and associations have been suggested: immunoglobulin deposition, direct HIV infection of endothelial cells, hyperviscosity due to red cell aggregation, fibrinogen, leukocyte rigidity, Pneumocystis carinii infection, alteration of hemodynamic factors, and secretion of proteolytic enzymes. ${ }^{24,46}$

Several testing methods, including the Heidelberg flow meter, blue field entopic phenomenon, and scanning laser ophthalmoscopy with fluorescein angiography, have measured retinal blood flow abnormalities in HIV patients. Macular blood flow appears to be diminished more than peripheral flow ${ }^{47}$ and both increased erythrocyte aggregation and leukocyte rigidity appear to contribute to these changes. Unfortunately these flow abnormalities are not reversed by HAART. ${ }^{48}$ Ophthalmoscopic examinations and technicium-99m-hexamethyl-propyleneamine oxide single photon emission computerized tomography of the brain showed a strong correlation between the number of CWSs and cerebral blood flow. ${ }^{49}$

It has been suggested that CWSs, which result from focal occlusions of the capillary bed, may serve as a portal for CMV entry to the retina. ${ }^{50}$ Since HIV retinopathy has proven to be a marker for subsequent CMV retinitis, some investigators have recommended that 
these patients receive eye examinations every 3 months. ${ }^{24}$

An autopsy study found high incidences of CMV retinitis (60\%), CWSs (36\%) and HIV encephalitis (20\%). ${ }^{46}$ Based upon these rates, the authors suggested that CMV retinitis may be a marker of HIV encephalitis. Surprisingly, HIV p24 antigen was detected in the brain, but could not be found in areas of CMV retinitis, CWSs, or retinal vascular endothelium. They pointed out that other immunochemical searches for HIV antigens in the retina have shown variable results with detection in up to only $31 \%$ of retinas in some series. ${ }^{51}$ They contend that direct infection of the retina and pigment epithelium by HIV may, therefore, be a rare occurrence, and that this low yield may represent false positive retina cultures due to the presence of infected leukocytes that secrete damaging factors or HIV damaged proteins. ${ }^{46,52,53}$

Other studies into whether or not HIV directly infects the retina have also reached conflicting conclusions. In the central nervous system HIV usually infects microglia but, except in some pathological conditions, these cells are conspicuously absent in the retina..$^{54}$ Experiments with human retinal microglia, however, have noted expression of $\mathrm{CD}^{+}$, $\mathrm{CD} 16+, \mathrm{CD} 64+, \mathrm{Cc} 5$ receptors in vitro and $\mathrm{Fc}$ lambda in vivo, thereby suggesting that HIV infection of retinal microglia contributes to neural damage and blood-retinal barrier breakdown. HIV infection of retinal pigment epithelial (RPE) cells upregulates phagocytosis. Since RPE cells are of neuroectodermal origin and, therefore, do not express $\mathrm{CD}^{+}{ }^{+}$receptors, HIV probably infects RPE cells at a low level via a CD4+ independent manner. ${ }^{23}$

In vivo studies of HIV infection have been limited because HIV is not pathogenic in other species. Experiments in which infected human tissue is placed in the anterior chamber of rats supports the theory that neuronal damage is mediated by infected monocytes. ${ }^{55}$

Continued HIV replication within the retina releases neurotoxins that cause apoptosis of specific retinal cells. This cascade hypothesis states that replicating viruses shed gp120 proteins which are cytotoxic to mammalian neurons and produce apoptosis ${ }^{56}$ at subpicomolar levels. ${ }^{57}$ HIV infected macrophages, gp120 stimulated macrophages and cell-to-cell interactions may instigate and amplify neurotoxic activities. ${ }^{57}$ This stimulates the production of pro-inflammatory cytokines, including interleukin-1, interleukin-6 and TNF- $\alpha$, which induce quinoloic acid production by macrophages, astroglia and other cells..$^{58,59}$ The cytotoxic effect of quinoloic acid leads to apoptosis, perhaps by disturbing glutamate metabolism or by producing reactive oxygen species thereby causing oxidative stress. ${ }^{60}$

Activated astrocytes in both the retina and brain release neurotoxic chemokines including CXCL10. Two regulators of CXCL10 expression include the inflammatory cytokines IFN- $\Upsilon$ and TNF- $\alpha$ both of which are present in infected tissues. Another upregulator of CXCL10 release is the HIV-1 protein, Tat. ${ }^{61}$ Media from Tat treated R28 retinal cells induces monocyte migration and HIV-1 Tat-transgenic mice demonstrate increased glial activation and a complete absence of the retinal photoreceptors and outer nuclear layer. ${ }^{62}$

The presence of these cytokines suggests that the mechanism of retinal damage is similar to that within the central nervous system. ${ }^{6}$ Rat neuronal cultures exposed to HIV proteins show a direct relationship between protein exposure, calcium channel activation and neurotoxicity. ${ }^{64}$ Neuronal damage could be prevented by both calcium channel antagonists ${ }^{52}$ and antibodies to the HIV envelope protein gp120.65 Autopsy studies show that central nervous system infection by HIV leads to loss of vascular and glial cells..$^{50}$

\section{Neuro-ophthalmologic findings}

Neurological findings are frequently seen in AIDS patients and are usually associated with infections such as toxoplasmosis or cryptococcus, or tumors such as lymphoma. HIV, however, can infect all parts of the central nervous system. It has been found within brain tissue, has been associated with chronic meningitis ${ }^{66}$ and causes vasculitis in the CNS and other tissues. ${ }^{67,68}$ Autopsy studies show patchy loss of myelin in the subcortical white matter, astroglial proliferation, and scattered macrophages, multinucleated giant cells and microglia. ${ }^{49}$ These findings are consistent with a progressive diffuse leukoencephalopathy in the majority of AIDS patients. ${ }^{25}$

Even in the absence of other organisms, the type and degree of HIV-induced cerebral damage is sufficient to cause dementia. Additionally, the degree of synaptic damage and cognitive disability appears proportional to the HIV burden. ${ }^{69,70}$ Together these studies suggest that HIV is, by itself, capable of causing dementia. An association may exist between diffuse leukoencephalopathy and HIVinduced damage to retinal neurons, but studies sufficient to confirm this have not been performed. ${ }^{54}$

Although neuro-ophthalmic disorders are found in only $3 \%$ to $8 \%$ of AIDS patients, ${ }^{71} 60 \%$ of patients with neurological disorders have abnormal neuro-ophthalmologic examinations. In fact most cases of smooth pursuit (78\%) and saccade (71\%) disorders within the AIDS population are due to HIV. Importantly, eye movement disorders may be an early sign of AIDS dementia.

Anterior ischemic optic neuropathy (AION) can result from multiple nerve fiber layer infarctions due to severe HIV retinopathy. However, a more common cause of optic atrophy in patients without significant retinopathy is AIDS-associated primary optic neuropathy. Generally up to $50 \%$ of axons within the optic nerve can be lost before the discs appear atrophic ${ }^{38}$ but even asymptomatic HIV patients have axonal loss out of proportion to their degree of demyelination. ${ }^{72}$

HIV-related optic neuropathy may occur more commonly than HIV retinopathy, as one autopsy study found HIV in $80 \%$ of optic nerves but only $20 \%$ of retinas. The fact that axonal degeneration of the optic nerve can occur in the absence of retinitis further confirms this belief. Whereas CWSs produce small islands of focal retinal degeneration, with loss of nerve fiber bundles in both the retina and optic nerves, the patchy, diffuse degeneration seen in the nerves of HIVinfected patients suggests a primary optic neuropathy rather than the anterograde degeneration caused by CWSs. ${ }^{25,72}$ Autopsy studies show glial changes, including hypertrophic astrocytes, vacuolated oligodendrocytes, and mononuclear phagocyte series cells.

Since viral particles have never been detected in axons either by electron microscopy ${ }^{25,73}$ or in situ hybridization, ${ }^{74}$ HIV neuropathy may be secondary to invasion by infected macrophages rather than direct damage due to HIV. ${ }^{25}$ In a manner similar to that proposed for retinal damage, invading macrophages may damage optic nerve axons by releasing neurotrophic factors (enzymes or cytokines), or directly releasing virions, enveloping glycoproteins, or inflammatory mediators. ${ }^{25}$ TNF- $\alpha$ appears to be a particularly potent modulator of neuronal apoptosis. ${ }^{75}$

HIV-related optic neuropathy occurs in $4 \%$ of AIDS patients with neurological findings and $7 \%$ of AIDS patients with neuro-ophthalmologic findings. ${ }^{71}$ Visual field loss that usually spares the papillomacular bundle has been discovered in $50 \%$ of these patients ${ }^{44,49,56}$ This pattern of predominantly superior and inferior field loss suggests that causative lesions are situated near the optic disc. ${ }^{77}$ The presence of an optic neuropathy does not appear to correlate with $\mathrm{CD} 44^{+}$counts. ${ }^{78}$ Supporting this finding is the observation that AIDS patients with neurological symptoms are not at higher risk of optic neuropathy than patients without symptoms.

Bilateral acute optic neuritis accompanied by exudative retinal detachments and macular edema has been associated with primary HIV infection. All of the reported cases responded to the institution of anti-HIV therapy. ${ }^{75,79-81}$

A chronic, remitting multiple sclerosis-like syndrome with optic neuritis has been 
described. Patients responded to intravenous corticosteroids with complete recovery. Based on this, the authors recommend a trial of systemic steroids for HIV patients with recurring optic neuritis, but suggest that because of the possibility of syphilis, physicians consider the concurrent administration of penicillin, even if patients are seronegative. ${ }^{82}$

Even asymptomatic patients with early HIV infection have electrophysiological and psychophysical abnormalities. Abnormal visual evoked potentials (VEPs) are seen in 57\% of patients with neurological symptoms and $42 \%$ of asymptomatic patients. The prolonged p100 latencies on VEPs suggest that these patients suffer from demyelination of the optic nerves. Additionally, patients often have loss of both contrast sensitivity and color vision. ${ }^{83-86}$ Cases of optic tract demyelination due to HIV have also been noted. ${ }^{87}$

Isolated cranial nerve palsies due to HIV are rare. A 37-year-old male patient developed an isolated trochlear nerve palsy which resolved after 2 months, a course which fits the criteria for a microvascular palsy. Histological findings in these cases consist of vascular endothelial cell swelling and increased cellularity which contribute to narrowing of the vessel lumen. Blood flow can be further compromised by perivascular and intravascular aggregation of HIV infected macrophages. ${ }^{88}$ Some authors believe that anti-retroviral therapy contributes directly to atherosclerosis. ${ }^{89}$

In a case involving multiple sensory pathways, a patient with early HIV infection (CD4 ${ }^{+}$ count of 720) was found to have progressive degeneration of the visual, auditory and corticospinal tracts..$^{90}$

\section{Drug toxicity}

A small number of patients have been described with retinal pigment epithelial and optic nerve abnormalities attributed to drug toxicity. Affected patients had advanced HIV disease $\left(\mathrm{CD}^{+}{ }^{+}\right.$lymphocyte counts $<200$ cells/ $\mu \mathrm{L}$ ) but no history of either HIV related eye disease or ocular opportunistic infection. Toxicity was attributed to a reverse transcriptase inhibitor or protease inhibitor, usually as part of HAART. Toxicity was first observed between 19 weeks and 5 years after initiation of the offending drug. This delayed response suggests that toxicity may be related to the cumulative dose of the drug, perhaps due to abnormal metabolism or excretion, rather than an idiosyncratic reaction.

Didanosine can cause progressive well-circumscribed loss of mid-peripheral retina, retinal pigment epithelium and choroid. ${ }^{91}$ Transmission electron microscopy of the retina shows lamellar inclusion bodies within the cytoplasm..$^{92}$ Deposits in the mid-peripheral retina were noted in 4 children receiving didanosine, one of whom had a depressed electro-oculogram. ${ }^{93}$ Annular visual field defects, corresponding to the areas of retinal atrophy, were seen. Discontinuing didanosine stabilizes the degeneration and normalizes the electro-oculogram. ${ }^{91,93}$ Didanosine has also been associated with optic neuropathy. ${ }^{94}$

Three patients receiving ritonavir developed retinal pigment epitheliopathy, macular parafoveal telangiectasia and intraretinal crystalline deposits with moderate loss of visual acuity. Since ritonavir is metabolized by the cytochrome p450 system, it is believed that prolonged serum drug levels due to hepatic insufficiency may cause the retinopathy. ${ }^{95}$

A single case of retinal whitening was described in a patient receiving efavirenz. ${ }^{89}$

\section{Anterior segment findings}

Though the retina is the most commonly affected ocular tissue, HIV patients commonly develop abnormalities of the cornea and anterior segment (50\%), and ocular adnexae (25\%). ${ }^{96}$ Commonly seen in the general population, blepharitis is both more common and more severe in HIV infected patients. Patients with B-cell deficiency are more commonly affected than those with T-cell deficiency, which may be due to either their reduced ability to clear flora or the more complex immunodeficiency-induced changes found in the tear glands. Jeng et al. reported chronic relapsing blepharitis in 3 patients a few months after starting indinavir. The patients experienced a drug-induced retinoid effect - desquamative or erosive chelitis, mucocutaneous xerosis, alopecia, asteatotic eczema, paronychia,

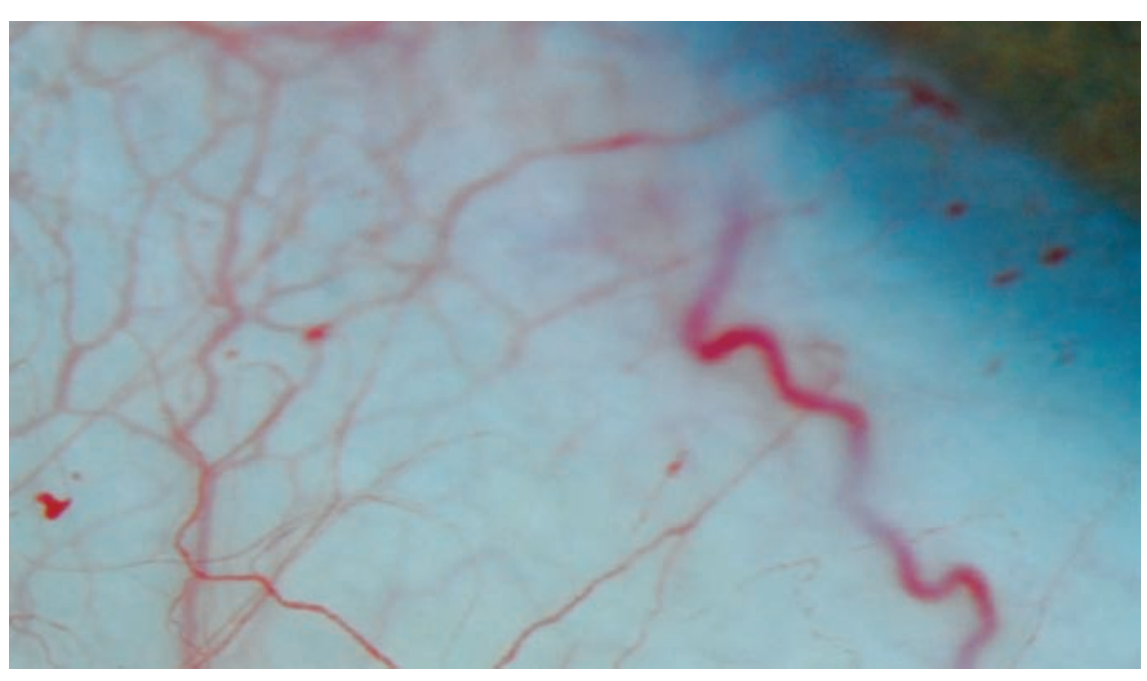

Figure 2. Microvascular abnormalities of the conjunctiva, such as these aneurysms, occur frequently. ingrown nails. Discontinuing the indinavir was followed by resolution of the blepharitis in 2 patients. ${ }^{97}$

Acquired tricomegaly (hypertrichosis of the eyelashes) in AIDS patients may be due to the use of several drugs. Some authors suggest that an HIV protein may stimulate keratocytes and pilosebaceous structures. Some even sugcate effective anti-retroviral therapy. ${ }^{97}$

Conjunctival vasculopathy is seen in $75 \%$ of AIDS patients (Figure 2). These generally benign abnormalities include microaneurysms, segmental venous dilation, and adjacent narrowing of arterioles, similar to changes seen in patients with sickle cell disease, leukemia and ataxia-telangiectasia. Radioassays of the vascular endothelium suggest the presence of endothelin-1.97

Keratoconjunctivitis sicca, dry eyes due to decreased aqueous tear production - seen in $<1 \%$ of the general population - has been found in $20 \%$ of HIV infected males and $17 \%$ of females. ${ }^{97,98}$ Most affected AIDS patients have lymphocytic infiltration of the lacrimal glands and direct HIV destruction of conjunctival cells. ${ }^{99}$ Some authors suggest that young patients without an underlying reason for $\mathrm{K}$ sicca should undergo HIV testing. ${ }^{99}$

Early discovery of HIV in the tears and contact lenses of AIDS patients raised concerns about possible HIV transmission with corneal transplantation, applanation tonometry and general examination techniques. ${ }^{100}$ Fortunately, most CDC recommended methods of contact (although come chemical methods have not been tested), will also eradicate HIV. ${ }^{101}$ Alcohol swabs, isopropyl alcohol, ethanol, and gluteraldehyde effectively eradicate HIV from contaminated surfaces including applanation tonometers. ${ }^{97}$ Since no cases of HIV transmission from gest that cessation of eyelash growth may indilens sterilization, heat and hydrogen peroxide 
tears or contact lenses have been reported, the Centers for Disease Control (CDC) have excluded tears from the list of fluids deemed to be infectious.

HIV is capable of infecting corneal and conjunctival epithelial cells in vivo and has been found in the cells of asymptomatic patients. ${ }^{101,102}$ Polymerase chain reaction has identified HIV in $18 \%$ of corneas and $6 \%$ of aqueous samples. Although HIV has been found in $2 \%$ to $3 \%$ of epithelial cells, ${ }^{103,104}$ the virus does not appear to enter via $\mathrm{CD} 4^{+}$or galC receptors. ${ }^{104}$

Since other viruses such as hepatitis B, rabies and Creutzfeld-Jacob have been transmitted via corneal transplantation, concerns over HIV transmission have naturally arisen. Current recommendations to determine the suitability of a donor include cadaveric testing with ELISA or Western Blot within 12 hours of death. ${ }^{105}$ Furthermore, tissue is rejected if the patient exhibited a history of high risk behavior. Fortunately, current ELISA screening of corneas for HIV is $99 \%$ sensitive and nearly $99 \%$ specific. $^{106}$ The use of these protocols results in rejection of up to $21 \%$ of corneas by eye banks, nearly one half of these are due to HIV and Hepatitis B virological testing. ${ }^{107}$ Although 10 corneas from HIV infected cadavers have been transplanted, none of the recipients has seroconverted. ${ }^{51}$

Patients with round and reticular posterior corneal infiltrates at the level of Descemet's membrane, smaller centrally and larger in the periphery, have been described. These have not been associated with inflammation. All reported patients were taking protease inhibitors, which are known to cause hyperlipidemia and lipodystrophy. ${ }^{108,109}$ Transient anterior corneal spots have also been described. ${ }^{110}$

Other patients have developed more severe corneal problems with bilateral peripheral corneal thinning leading to perforation. ${ }^{111}$ Another patient developed peripheral ulceration associated with a hypopyon. A biopsy showed immune complex deposition within the corneal stroma but no organisms. One patient presented with both peripheral corneal ulceration and a central retinal vein occlusion. ${ }^{112}$

An epibulbar granulomatous nodule of the conjunctiva containing inflammatory material and an eosinophilic abscess has been described. ${ }^{113}$ Nevirapine, a common first-line anti-retroviral drug, can cause StevensJohnson syndrome which severely damages the conjunctiva in two thirds of cases. ${ }^{114}$

Iris and macular crystalline deposits have been described in a patient with benign hypergammaglobulinemia. The authors hypothesized that HIV-mediated breakdown of the blood-retinal barrier enabled crystal deposition within interstitial tissues. ${ }^{115}$ The idea of BRB breakdown is supported by the presence of HIV in the iris despite treatment with zidovudine. ${ }^{15}$
HIV infected transgenic mice were found to have swelling and vacuolization of lens fiber cells, without associated inflammation, at 3-6 months of age. Large amounts of p24 GAG protein were found in both the lens and retina. ${ }^{116}$ Since the introduction of HAART, cataracts have become an increasingly important reason for vision loss and their incidence does not seem to depend upon the presence of IRU. ${ }^{44}$

HIV is believed to enter the eye via infected macrophages ${ }^{117}$ and may then find temporary sanctuary from the body's immune system. ${ }^{118}$ Intraocular HIV was detected in $32 \%$ of AIDS patients with uveitis, with higher levels in patients with retina lesions and lower levels in patients on HAART for at least 2 months. Uveitis may be anterior or combined anterior/posterior and are typically bilateral (10 eyes of 6 patients). Though none of these eyes responded to corticosteroids, all responded favorably to the initiation of zidovudine therapy. All 4 patients whose intraocular fluids ( 3 aqueous and 1 vitreous) were cultured tested positive for the HIV p24 antigen ${ }^{119}$ A 37year-old uveitis patient with a $\mathrm{CD} 4^{+}$count of 122 cells/ $\mu \mathrm{L}$ and a serum viral load of 44,000 copies/mL was found to have an intraocular HIV load of 1.9 million copies/mL. ${ }^{120}$ Intraocular HIV replication, as indicated by intraocular viral loads greater than those in the serum, also occurs in patients with retinitis. ${ }^{121,122}$

HIV causes rheumatic syndromes in both children and adults by directly infecting the joints, activating the immune system, or by influencing genetic or environmental factors. ${ }^{123}$ Affected children may have pauciarticular or polyarticular arthritis, and anterior or intermediate uveitis. Because of the high correlation between arthritis and uveitis, some authors now perform uveitis screening on all HIV patients with arthritis. ${ }^{124}$

Whereas transient elevation of the CD8+ count due to HIV infection may commonly occur, persistent CD8+ lymphocytosis (diffuse infiltrative lymphocytosis syndrome (DILS)) is occasionally seen. Four patients with panuveitis and CD8+ lymphocytosis have been described. Fortunately, DILS is associated with a slower progression to AIDS and fewer opportunistic infections.

\section{Conclusions}

The introduction of HAART significantly decreased the incidence of opportunistic infections, especially those affecting the visual system. Although the overall prevalence of vision loss among AIDS patients has decreased, the proportion of patients suffering loss of vision due to HIV has increased. HIV-related ophthalmologic disorders should, therefore, be considered in patients with new ocular complaints or findings, or in at-risk patients with unusual ocular diseases.

\section{References}

1. Gottlieb MS, Schroff R, Schanker HM, et al. Pneumocystis carinii pneumonia and mucosal candidiasis in previously healthy homosexual men: evidence of a new acquired cellular immunodeficiency. N Engl J Med 1981;305:1425-31.

2. Masur H, Michelis MA, Greene JB, et al. An outbreak of community-acquired Pneumocystis carinii pneumonia: Initial manifestation of cellular immune dysfunction. $\mathrm{N}$ Engl J Med 1981;305:1431-8.

3. Definition of HAART. 2004. Available from: http://statepiaps.jhsph.edu/wihs/Investinfo/Def-haart.pdf

4. Jabs DA. AIDS and Ophthalmology in 2004. Arch Ophthalmol 2004;122:1041-2.

5. Kempen JH, Min YI, Freeman WR, et al. Risk of immune recovery uveitis in patients with AIDS and cytomegalovirus retinitis. Ophthalmology 2006;113:684-94.

6. Thorne JE, Holbrook JT, Jabs DA, et al. Effect of cytomegalovirus retinitis on the risk of visual acuity loss among patients with AIDS. Ophthalmology 2007;114:591-8.

7. Cunningham ET Jr, Levinson RD, Jampol LM, et al. Ischemic maculopathy in patients with acquired immunodeficiency syndrome. Am J Ophthalmol 2001;132:72733 .

8. Holland GN, Vaudaux JD, Shiramizu KM, et al. Characteristics of untreated AIDSrelated cytomegalovirus retinitis. II. Findings in the era of highly active antiretroviral therapy (1997 to 2000). Am J Ophthalmol 2008;145:12-22.

9. Stewart MW. Optimal management of cytomegalovirus retinitis in patients with AIDS. Clin Ophthalmol 2010;4:285-99.

10. Stewart MW. Impact of HIV on vision. Northeast Florida Medicine 2011;62:3-8.

11. Hughes MD, Johnson VA, Hirsch MS, et al. Monitoring plasma HIV-1 RNA levels in addition to $\mathrm{CD}^{+}$lymphocyte count improves assessment of antiretroviral therapeutic response. ACTG 241 Protocol Virology Substudy Team. Ann Intern Med 1997;126:929-38.

12. Connors M, Kovacs JA, Krevat S, et al. HIV infection induces changes in CD4+ T-cell phenotype and depletions within the CD4+ T-cell repertoire that are not immediately restored by antiviral or immunebased therapies. Nat Med 1997;3:533-40.

13. Goldberg DE, Smithen LM, Angelilli A, Freeman WR. HIV-associated retinopathy in the HAART era Retina 2005;25:633-49.

14. Nussenblatt RB, Lane HC. Human immun- 
odeficiency virus disease: changing patterns of intraocular inflammation. Am J Ophthalmol 1998;125:374-82.

15. Cantrill HL, Henry K, Jackson B, et al. Recovery of human immunodeficiency virus from ocular tissues in patients with acquired immune deficiency syndrome. Ophthalmology 1988;95:1458-62.

16. Williams KC, Hickey WF. Central nervous system damage, monocytes and macrophages, and neurological disorders in AIDS. Annu Rev Neurosci 2002:25:537-62.

17. Hult B, Chana G, Masliah E, Everall I. Neurobiology of HIV. Int Rev Psychiatry 2008;20:3-13

18. Alexaki A, Liu Y, Wigdahl B. Cellular reservoirs of HIV-1 and their role in viral persistence. Curr HIV Res 2008;6:388-400.

19. Kida S, Steart PV, Zhang ET, Weller RO. Perivascular cells act as scavengers in the cerebral perivascular spaces and remain distinct from pericytes, microglia and macrophages. Acta Neuropathol (Berl) 1993;85:646-52.

20. Harling-Berg C, Knopf PM, Merriam J, Cserr HF. Role of cervical lymph nodes in the systemic humoral immune response to human serum albumin microinfused into rat cerebrospinal fluid. J Neuroimmunol 1989;25:185-93.

21. Garden GA. Microglia in human immunodeficiency virus-associated neurodegeneration. Glia 2002;40:240-51.

22. Eugenin EA, Osiecki K, Lopez L, et al. CCL2/monocyte chemoattractant protein-1 mediates enhanced transmigration of human immunodeficiency virus (HIV)infected leukocytes across the blood-brain barrier: A potential mechanism of HIVCNS invasion and NeuroAIDS. J Neuroscience 2006;26:1098-106.

23. Canki M, Sparrow JR, Chao W, et al. Human immunodeficiency virus type 1 can infect human retinal pigment epithelial cells in culture and alter the ability of the cells to phagocytose rod outer segment membranes. AIDS Res Hum Retroviruses 2000;16:453-63.

24. Vrabek TR. Posterior segment manifestations of HIV/AIDS. Surv Ophthalmol 2004 49:131-57.

25. Sadun AA, Pepose JS, Madigan MC, et al. AIDS-related optic neuropathy: a histological, virological and ultrastructural study. Graefe's Arch Clin Exp Ophthalmol 1995;233:387-98.

26. O'hara MA, Raphael SA, Nelson LB. Isolated anterior uveitis in a child with acquired immunodeficiency syndrome. Ann Ophthalmol 1991;23:71-3.

27. Iragui VJ, Kalmijn J, Plummer DJ, et al. Pattern electroretinograms and visual evoked potentials in HIV infection: evidence of asymptomatic retinal and postretinal impairment in the absence of infectious retinopathy. Neurology 1996;47: 1452-6.

28. Roth D, McCabe CM, Davis JL. HIV-related occlusive vasculitis. Arch Ophthalmol 1999;117:696-8.

29. Yoganathan K, Austin M. Ischemic maculopathy in zidovudine-induced anemia in an HIV-positive man. Clin Ophthalmol 2008;2:237-9.

30. Levinson RD, Vann R, Davis JL, et al. Chronic multifocal retinal infiltrates in patients infected with human immunodeficiency virus. Am J Ophthalmol 1998;25:3 12-24.

31. Fineman MS, Emerick G, Dudley D, et al. Bilateral choroidal effusions and angleclosure glaucoma associated with human immunodeficiency virus infection. Retina 1997;17:455-7.

32. Park KL, Marx JL, Lopez PF, Rao NA. Noninfectious branch retinal vein occlusion in HIV-positive patients. Retina 1997;17:162-4.

33. Dunn JP, Yamashita A, Kempen JH, et al. Retinal vascular occlusion in patients infected with human immunodeficiency virus. Retina 2005;25:759-66.

34. Hendrickson SL, Jabs DA, Van Natta M, et al. Mitochondrial haplogroups are associated with risk of neuroretinal disorder in HIV-positive patients. J Acquir Immune Defic Syndr 2010;53:451-5.

35. Miura T, Goto M, Hosoya N, et al. Depletion of mitochondrial DNA in HIV-1-infected patients and its amelioration by antiretroviral therapy. J Med Virol 2003;70:497-505.

36. Jaruga P, Jaruga B, Gackowski D, et al. Supplementation with antioxidant vitamins prevents oxidative modification of DNA in lymphocytes of HIV-infected patients. Free Radic Biol Med 2002;32:41420.

37. Mackey DA, Fingert JH, Luzhansky JZ, et al. Leber's hereditary optic neuropathy triggered by antiretroviral therapy for human immunodeficiency virus. Eye 2003;17:312-7.

38. Kozak I, Bartsch D-U, Cheng L, et al. Objective analysis of retinal damage in HIV-positive patients in the HAART era using OCT. Am J Ophthalmol 2005;139: 295-301.

39. Gomez ML, Mojana F, Bartsch D-U, Freeman WR. Imaging of long-term retinal damage after resolved cotton wool spots. Ophthalmology 2009;116:2407-14.

40. Arantas TE, Garcia CR, de Arruda Mello PA, Muccioli C. Structural and functional assessment in HIV-infected patients using optical coherence tomography and frequency-doubling technology perimetry. Am J 0phthalmol 2010;149:571-6.

41. Honrubia FM, Ferrer E, Torron C, Gonzalez
I. Study of the retinal fiber layer in patients with acquired immunodeficiency syndrome. Ger J Ophthalmol 1994;3:1-4.

42. Falkenstein IA, Bartsch D-U, Azen SP, et al. Multifocal electroretinography in HIV-positive patients without infectious retinitis. Am J Ophthalmol 2008;146:579-88.

43. Goldbaum MH, Falkenstein I, Kozak I, et al. Analysis with support vector machine shows HIV-positive subjects without infectious retinitis have mfERG deficiencies compared to normal eyes. Trans Am Ophthalmol Soc 2008;106:16-205.

44. Freeman WR, Van Natta ML, Jabs D, et al. Vision function in HIV-infected individuals without retinitis: report of the studies of ocular complications of AIDS Research Group. Am J Ophthalmol 2008;145:453-62.

45. Glasgow BJ, Weisberger AK. A quantitative and cartographic study of retinal microvasculopathy in acquired immunodeficiency syndrome. Am J Ophthalmol 1994:46-56.

46. Faber DA, Wiley CA, Lynn GB, et al. Role of HIV and CMV in the pathogenesis of retinitis and retinal vasculopathy in AIDS patients. Invest Ophthalmol Vis Sci 1992; 33:2345-53.

47. Lim MC, Cumberland WG, Minassian SL, et al. Decreased macular leukocyte velocity in HIV-infected individuals. Am J Ophthalmol 2001;132:710-8.

48. Dagostar H, Holland GN, Huang X, et al. Hemorheologic abnormalities associated with HIV infection: in vivo assessment of retinal microvascular blood flow. Invest Ophthalmol Vis Sci 2006;47:3933-8.

49. Geier SA, Schielke E, Klauss V, et al. Retinal microvasculopathy and reduced cerebral blood flow in patients with acquired immunodeficiency syndrome. Am J Ophthalmol 1992;113:100-1.

50. Pepose JS, Holland GN, Nestor MS, et al. Acquired immune deficiency syndrome: pathogenic mechanisms of ocular disease. Ophthalmology 1985;92:472-84.

51. Garcia-Ferrer FJ, Laycock KA, Buerger DG, et al. Screening corneas for human immunodeficiency virus type 1 proviral DNA by polymerase chain reaction. Am J Ophthalmol 1995;119:7-13.

52. Lipton SA. Requirement for macrophages in neuronal injury induced by HIV envelope protein gp120. Neuroreport 1992;3: 913-5.

53. Giulian D, Vaca K, Noonan CA. Secretion of neurotoxins by mononuclear phagocytes infected with HIV-1. Science 1990;250:1593-996.

54. Hammond RR, Achim CL, Wiley CA. Neuropathology of the retina in acquired immunodeficiency syndrome. Semin Ophthalmol 1995;10:177-82.

55. Cvetkovich TA, Lazar E, Blumberg BM, et al. Human immunodeficiency virus type 1 
infection of neural xenografts. Proc Natl Acad Sci USA 1992;89:5162-6.

56. Plummer DJ, Sample PA, Arevalo JF, et al. Visual field loss in HIV-positive patients without infectious retinopathy. Am J Ophthalmol 1996;122;542-9.

57. Gendelman HE, Lipton SA, Tardieu M, et al. The neuropathogenesis of HIV-1infection. J Leukocyte Biol 1994;56:389-98.

58. Petrovich MS, Hsu HY, Gu X, et al. Pentoxifylline suppression of TNF-alpha mediated axonal degeneration in the rabbit optic nerve. Neurol Res 1997;19:551-4.

59. Madigan MC, Rao NS, Tenhula WN, Sadun AA. Preliminary morphometric study of tumor necrosis factor-alpha (TNF alpha)induced rabbit optic neuropathy. Neurol Res 1996;18:233-6.

60. Price TO, Recall N, Akanke R, Banks WA. HIV-1 viral proteins gp120 and Tat induce oxidative stress in brain endothelial cells. Brain Res 2005;1045:57-63.

61. Williams R, Yao H, Dhillon NK, Buch SJ. HIV-1 Tat c-operates with IFN- $\Upsilon$ and TNF$\alpha$ to increase CXCL10 in human astrocytes. PLOS One 2009;4:e5709.

62. Chatterjee N, Callen S, Seigel GM, Buch SJ. HIV-1 Tat-mediated neurotoxicity in retinal cells. J Neuroimmune Pharmacol 2011;6:399-408.

63. Hofman FM, Hinton DR. Tumor necrosis factor-alpha in the retina in acquired immune deficiency syndrome. Invest Ophthalmol Vis Sci 1992;33:1829-35.

64. Dreyer EB, Kaiser PK, Offermann JT, et al. HIV-1 coat protein neurotoxicity prevented by calcium channel. Science 1990;248:3647.

65. Kaiser PK, Offermann JT, Lipton SA. Neuronal injury due to HIV-1 envelope protein is blocked by anti-gp120 antibodies but not by anti-CD4 antibodies. Neurology 1990;40:1757-61.

66. Ho DD, Rota TR, Schooley RT, et al. Isolation of HTLV-III from cerebrospinal fluid and neural tissues of patients with neurologic syndromes related to the acquired immunodeficiency syndrome. $\mathrm{N}$ Engl J Med 1985;313:1493-97.

67. Bernard E, Dellamonica P, Michiels JF, et al. Heparin-like anti-coagulant vasculitis associated with severe primary infection by HIV. AIDS 1990;4:932-3.

68. Calabrese LH. Vasculitis and infection with the human immunodeficiency virus. Rheum Dis Clin North Am 1991;17:131-7.

69. Wiley CA, Achim CL. HIV encephalitis is the pathologic correlate of dementia in AIDS. Ann Neurol 1994;36:673-6.

70. Masliah E, Achim CL, Ge N, et al. Spectrum of human immunodeficiency virus-associated neocortical damage. Ann Neurol 1992;32:321-9.

71. Mwanza J-C, Nyamabo LK, Tylleskar T,
Plant GT. Neuro-ophthalmological disorders in HIV infected subjects with neurological manifestations. Br J Ophthalmol 2004;88:1455-9.

72. Mahadevan A, Satishchandra P, Prachet KK, et al. Optic nerve axonal pathology is related to abnormal visual evoked responses in AIDS. Acta Neuropathol 2006;112: 461-9.

73. Skolnik PR, Pomerantz RJ, de la Monte SM, et al. Dual infection of retina with human immunodeficiency virus type 1 and cytomegalovirus. Am J Ophthalmol 1989; 107:361-72.

74. Kennedy PG, Newsome DA, Hess J, et al. Cytomegalovirus but not human T lymphotropic virus type III/ymphadenopathy associated virus detected by in situ hybridization in retinal lesions in patients with the acquired immune deficiency syndrome. Br Med J 1986;293:162-4.

75. Goldsmith P, Jones RE, Ozuzu GE, et al. Optic neuropathy as the presenting feature of HIV infection: recovery of vision with highly active antiretroviral therapy. Br J Ophthalmol 2000;84:551-3.

76. Geier SA, Nohmeier C, Lachenmayr BJ, et al. Deficits in perimetric performance in patients with symptomatic human immunodeficiency virus infection or acquired immunodeficiency syndrome. Am J Ophthalmol 1995;119:335-44.

77. Kozak I, Sample PA, Hao J, et al. Machine learning classifiers detect subtle field defects in eyes of HIV individuals. Trans Am 0phthalmol Soc 2007;105:111-20.

78. Sample PA, Plummer DJ, Mueller AJ, et al. Pattern of early visual field loss in HIVinfected patients. Arch Ophthalmol 1999; 117:755-60.

79. Larsen M, Toft PB, Bernhard P, Herning M. Bilateral optic neuritis in acute human immunodeficiency virus infection. Acta Ophthalmol Scand 1998;76:737-8.

80. Stewart MW, Brazis PW, Barrett KM, et al. Optical coherence tomography in a case of bilateral neuroretinitis. J Neuroophthalmol 2005;25:131-3.

81. Forooghian F, Lam W-C, Hopkins J, Dhanda D. Bilateral neuroretinitis with perpapillary serous retinal detachments in a patient with HIV and HBV. Arch Ophthalmol 2005;123:1447-9.

82. Burton BJL, Leff AP, Plant GT. Steroidresponsive HIV optic neuropathy. J Neuroophthalmol 1998;18:25-9.

83. Quinceno JI, Capparelli E, Sadun AA, et al. Visual dysfunction without retinitis in patients with acquired immunodeficiency syndrome. Am J Ophthalmol 1992;113:813.

84. Mueller AJ, Plummer DJ, Dua R, et al. Analysis of visual dysfunctions in HIV-positive patients without retinitis. Am J
Ophthalmol 1997;124:158-67.

85. Geier SA, Kronawitter U, Bogner JR, et al. Impairment of colour contrast sensitivity and neuroretinal dysfunction in patients with symptomatic HIV infection or AIDS. Br J Ophthalmol 1993;77:716-20.

86. Geier SA, Hammel G, Bogner JR, et al. HIVrelated ocular microangiopathic syndrome and color contrast sensitivity. Invest Ophthalmol Vis Sci 1994;35:3011-21.

87. Rhodes RH. Histopathology of the central nervous system in the acquired immunodeficiency syndrome. Hum Pathol 1987;18: 636-43.

88. Moulignier A, Laloum L, Chauveau E, et al. HIV-1 related ischaemic trochlear nerve palsy. J Neurol 2003;250:108-9.

89. Lewis A, Mitchell S. Efavirenz and retinal toxicity (Letter). Eye 2002;16:107.

90. Kleffner I, Wersching H, Schwindt W, et al. Triad of visual, auditory and corticospinal tract lesions: a new syndrome in a patient with HIV infection. AIDS 2011;25:659-63.

91. Whitcup SM, Dastgheib, K, Nussenblatt $\mathrm{RB}$, et al. A clinicopathologic report of the retinal lesions associated with didanosine. Arch Ophthalmol 1994;112:1594-8.

92. Zeldin RK, Petruschke RA. Pharmacological and therapeutic properties of ritonavirboosted protease inhibitor therapy in HIVinfected patients. J Antimicrob Chemother 2004;53:4-9.

93. Cobo J, Ruiz MF, Figueroa MS, et al. Retinal toxicity associated with didanosine in HIV-infected adults. AIDS 1996;10: 1297-300.

94. Lafeuillade A, Aubert L, Chaffanjon P, Quilichini R. Optic neuritis associated with dideoxyinosine. Lancet 1991;337:615-6.

95. Roe RH, Jumper JM, Gualino V, et al. Retinal pigment epitheliopathy, macular telangiectasis, and intraretinal crystal deposits in HIV-positive patients receiving ritonavir. Retina 2011;31:559-65.

96. Biswas J, Sudharshan S. Anterior segment manifestations of human immunodeficiency virus/acquired immune deficiency syndrome. Ind J 0phthalmol 2008;56:363-75.

97. Jeng BH, Holland GN, Lowder CY, et al. Anterior segment and external ocular disorders associated with human immunodeficiency virus disease. Surv Ophthalmol 2007;52:329-368.

98. Lucca JA, Kung JS, Farris RL. Kerato-conjunctivitis sicca in female patients infected with human immunodeficiency virus. CLAO J 1994;20:49-51.

99. Ormerod LD, Dailey JP. Ocular manifestations of cat-scratch disease. Curr Opin Ophthalmol 1999;10:209-16.

100. Fujikawa LS, Salahuddin SZ, Palestine AG, et al. Isolation of human T-lymphotropic virus type III from the tears of a patient with the acquired immunodeficiency syn- 
drome. Lancet 1985;2:529-30.

101.Slonim CB. AIDS and the contact lens practice. CLAO J 1995;21:233-5.

102.Ablashi DV, Sturzenegger S, Hunter EA, et al. Presence of HTLV-III in tears and cells from the eyes of AIDS patients. J Exp Path 1987;3:693-703.

103.Salahuddin SZ, Palestine AG, Heck E. Isolation of human T-cell leukemia/lymphotrophic virus type III from cornea. Am J Ophthalmol 1986;101:149-52.

104.Qavi HB, Xu B, Green MT, et al. Morphological and ultrastructural changes induced in corneal epithelial cells by HIV-1 and HHV-6 in vitro. Curr Eye Res 1996;15: 597-604.

105.Challine D, Roudot-Thoraval F, Sabatier P, et al. Serological viral testing of cadaveric cornea donors. Transplantation 2006;82: 788-93.

106.Pepose JS, Pardo F, Kessler JA II, et al. Screening cornea donors for antibodies against human immunodeficiency virus: efficacy of ELISA testing of cadaveric sera and aqueous humor. Ophthalmology 1987; 94:95-100.

107.Saldanha B0, Oliveira RE Jr, Araujo PLP, et al. Causes of nonuse of corneas donated in 2007 in Minas Gerais. Transplant Proc 2009;41:802-3.

108.Chu DS, Zaidman, GW, Meisler DM, et al. Human immunodeficiency virus-positive patients with posterior intracorneal precipitates. Ophthalmology 2001;108:1853-7.
109.Thorne JE, Shah KH, Brown DM, et al. Posterior intracorneal opacities in patients with HIV infection. Ocul Immunol Inflamm 2005;13:25-31.

110.Peebo BB, Fagerholm P, Lagali N. Transient anterior corneal deposits in a human immunodeficiency virus-positive patient. Cornea 2010;29:1323-7.

111. Raina UK, Sharma V, Jain S, et al. Peripheral corneal thinning and silent corneal perforation in an HIV seropositive case. Acta Ophthalmologica Scandinavica 2004;82:246-7.

112.Gharai S, Venkatesh P, Tandon R, Garg S. Peripheral ulcerative keratitis and central retinal vein occlusion as the initial manifestation of HIV infection. Ocul Immunol Inflamm 2007;15:407-9.

113.Godfrey DG, Carr JD, Grossniklaus HE. Epibulbar allergic granulomatous nodules in a human immunodeficiency virus-positive patient. Am J Ophthalmol 1998;126: 844-6.

114.Jain V, Shome D, Natarajan S. Nevirapineinduced Stevens-Johnson Syndrome. Cornea 2008;27:366-7.

115.Traill A, Zamir E, Russell D. Intraocular crystals in HIV-related hypergammaglobulinemia. Ocul Immunol Inflamm 2006;14: 63-5.

116.Iwakura Y, Shioda T, Tosu M, et al. The induction of cataracts by HIV-1 in transgenic mice. AIDS 1992;6:1069-75.

117.Pierson T, McArthur J, Siliciano RF.
Reservoirs for HIV-1: mechanisms for viral persistence in the presence of antiviral immune responses and antiretroviral therapy. Ann Rev Immunol 2000;18:665-708.

118.Pathanapitoon K, Riemens A, Kongyai N, et al. Intraocular and plasma HIV-1 loads and HIV uveitis. AIDS 2011;25:81-6.

119.Rosberger DF, Heinemann MH, Friedberg DN, Holland GN. Uveitis associated with human immunodeficiency virus infection. Am J Ophthalmol 1998;125:301-5.

120.Rothova A, Schneider M, de Groot-Mijnes JDF. Human immunodeficiency virusinduced uveitis: intraocular and plasma human immunodeficiency virus-a RNA loads. Ophthalmology 2008;115:2062-4.

121.Ciulla TA, Schnizlein-Bick CT, Danis RP, et al. Comparison of intraocular to plasma HIV-1 viral burden in patients with cytomegalovirus retinitis. Am J Ophthalmol 1999;127:221-3.

122.Hsu WM, Chiou SH, Chen SS, et al. The HIV RNA levels of plasma and ocular fluids in AIDS patients with ophthalmic infections. Ophthalmologica 2004;218:328-32.

123.Chinniah K, Mody GM, Bhimma R, Adhikari M. Arthritis in association with human immunodeficiency virus infection in black African children: causal or coincidental? Rheumatology 2005;44:915-20.

124.Zaborowski AG, Parbhoo D, Chinniah K, Visser L. Uveitis in children with human immunodeficiency virus-associated arthritis. JAAPOS 2008;12:608-10. 